\title{
Student Perceptions of Engineering Service Experiences as a Source of Learning Technical and Professional Skills
}

\author{
Adam Carberry \\ Assistant Professor, College of Technology \& Innovation, Department of Engineering \\ Arizona State University \\ Mesa, AZ 85212 \\ adam.carberry@asu.edu \\ Hee-Sun Lee \\ Visiting Assistant Professor, Department of Physics \\ University of California - Santa Cruz \\ Santa Cruz, CA 95064 \\ hlee58@ucsc.edu \\ Christopher Swan \\ Associate Professor, Department of Civil \& Environmental Engineering \\ Tufts University \\ Medford, MA 02155 \\ chris.swan@tufts.edu
}

Abstract - A dramatic increase in engineering student participation during the last decade indicates heightened student and faculty interest in engineering service experiences. The first step towards understanding why students are drawn to such opportunities is to examine how students perceive engineering service experiences as an important source of learning technical and professional skills involved in the engineering disciplines. The following study investigates how students compare their service experience with their traditional coursework experience as a source of learning professional and technical skills in engineering. Students' perception of where they learned professional and technical knowledge or skills provides an insight into the potential impact service-based interventions creates. This study compares service experiences with traditional coursework-based learning to examine the impact of service on students' perception of learning sources. Students participating in an eclectic and large variety of engineering service experiences were surveyed. Engineering students on average identified that $45 \%$ of what they have learned about technical skills and $62 \%$ of what they have learned about professional skills was gained through their engineering service experience. Female students credited service experiences as their source of both professional and technical skills significantly higher than male students, and were consistent across academic years. Engineering students' perceive service-based learning experiences, relative to their traditional course-based learning, to significantly impact what they know about technical and professional engineering outcomes.

Index Terms - service learning, technical and professional learning outcomes, self-perceptions 


\section{INTRODUCTION}

Engineering pertains to the human-built world with the goal of bettering life. This goal makes it important for engineering educators to introduce the idea of public service so that students can recognize the potential impact their profession can have on society. The inherent civic responsibility that comes along with being an engineer has led many engineering educators to expose students to engineering-specific service experiences. These naturally idiosyncratic learning experiences of service in the context of engineering education is slightly different across environments such as course-based, co-curricular, or extracurricular. ${ }^{1}$ Service is an umbrella term through which students learn engineering skills. What is lacking in the literature is a clear understanding of how students participating in service experiences perceive the opportunity as an avenue to learn engineering skills. This study fills this major gap in the literature by investigating the following two research questions:

1. How do students rate their engineering service experience compared to traditional coursework as a source of learning technical and professional skills related to engineering?

2. How do student perceptions of engineering service experiences as a source of learning vary by gender and academic year?

We present a background and literature review that includes a definition and brief history of service in engineering education. We then present a theoretical framework examining perceptions of learning and engineering learning outcomes, followed by a description of the research methods used for instrument development and analysis. Finally, we present results regarding each research question and discuss limitations and implications of the research.

\section{BACKGROUND AND LITERATURE REVIEW}

It is important to first understand how service-based learning is defined before investigating its impact on education. The following section will define service-based learning broadly to clearly identify what it entails and the theory behind the approach. The definition, history, and implementation will provide a foundation for why service can provide a valuable learning opportunity for students and supply support for why a study of these efforts in engineering was greatly needed.

\section{Definition}

Service-based learning in engineering disciplines essentially utilizes service as a vehicle for professional and technical knowledge gains. A precise description of how service is used in engineering is difficult due to the diverse approaches taken by these programs in development, implementation, and outcomes. Experiences have been grouped into three categories: 1) coursebased service learning, 2) co-curricular service experiences, and 3) extracurricular service experiences. Course-based service learning is described as a method of teaching, pedagogy, philosophy, and academic strategy embedded in traditional classroom environments. ${ }^{2-10} \mathrm{Co}$ curricular and extracurricular service experiences are activities partially embedded or 
completely separated from a traditional classroom environment that students participate in on a voluntary basis. The explicit embeddedness of service-learning within the curriculum creates a clear divide between co-curricular and extracurricular service experiences.

We define engineering service experiences (ESE) based on the overarching goals of the experience rather than on the proximity to the classroom. Programs defined as ESE for this study meet the criteria defined by Boyer ${ }^{11}$ and Jacoby ${ }^{6}$ : (a) be personally meaningful and real to the student, (b) incorporate elements of active citizenship directed toward school and community, (c) have clearly stated educational objectives (d) promote skills associated with teamwork and citizenship (cooperative rather than competitive experiences), (e) focus on addressing complex problems in complex settings, (f) engage students in problem solving and critical thinking, (g) teach a specific context of an activity, and (h) allow students to react to their experiences to promote deep learning through reflection, while disregarding setting and assessment. These goals reflect the principle that "service, combined with learning, adds value to each and transforms both"12 - especially when students recognize the relationship between service and their own learning. ${ }^{13}$ Programs like episodic volunteering, add-ons to school curriculum, community service, or compensatory service assigned as punishment do not fully align with these goals. Students who were involved in such programs were not included in this study. Only engineering service opportunities that reflect these goals and have the potential to enhance student learning outcomes desired by engineers were included.

\section{History of Service Learning in Engineering}

The use of service to enhance learning can be traced back to the mid-1800s, but it wasn't until 1964 that the term service learning was first used by the Oak Ridge Associated Universities as a way to describe their community service programs. ${ }^{14}$ This application of the term grew as many institutions in the United States adopted the terminology, leading to a number of educational programs focused on service learning. Federal programs, such as the University Year for Action (1972) and the National Center for Service Learning (1970) continued the growth in popularity of service-based educational efforts. In 1985, Campus Compact was formed as a consortium of college and university presidents who supported the value of service in education and on their campuses. Today, service-learning efforts have grown substantially at the elementary, secondary, and higher education levels.

The use of service in engineering education in the United States began in the 1990's (e.g., see Tsang et al. ${ }^{15}$ and Duffy ${ }^{16}$ ). These service-based efforts have included course-based service learning, co-curricular service experiences, and extracurricular opportunities used in a number of engineering disciplines at various different institutions. Some examples of exemplary programs include:

- Engineering Projects in Community Service (EPICS) is a program developed in 1995 at Purdue University. The program now exists at many other institutions as well as numerous high schools across the country (engineering.purdue.edu/EPICSU).

- The Service Learning Integrated throughout a College of Engineering (SLICE) program at the University of Massachusetts Lowell is an example of incorporating service learning into existing required courses. Undergraduates must take at least one course with a service experience in every semester (slice.uml.edu). 
- Engineers Without Borders (EWB) is a humanitarian, capacity-building organization which partners with developing communities to improve their quality of life (www.ewbusa.org).

- Engineers for a Sustainable World (ESW) is an organization that seeks to foster sustainable methods to improve the world's condition and quality of life through engineering (www.eswusa.org).

Engineering learning opportunities that utilize a service component have increased in the United States based on the need to reconsider the priorities of the professoriate, ${ }^{17}$ a desire to improve human conditions to fulfill higher education goals, ${ }^{18}$ and to meet the interest and demand of students and faculty across the nation. The increase in opportunities has also placed greater emphasis on studying the impact of these interventions to maximize the benefits of service experiences and to measure the value added. ${ }^{19-20}$

\section{THEORETICAL FRAMEWORK}

An assessment on the impact of service requires an understanding of not only 'how to' assess but also 'what to' assess. The theoretical framing for this study includes a description on the importance of using perceptions as a lens to investigate impact as well as a discussion on what skills it is believed engineering graduates should possess upon graduation.

\section{Perceptions of Learning}

Engineering students encounter many formal and informal learning experiences throughout their higher education. This makes it extremely difficult to pinpoint exactly where a student learned a particular set of knowledge or skills. Self-perceived sources of learning are a measure of where a student believes he or she has learned a specific skill or understanding. Self-perception is used for this study to identify sources of learning on a student's own account as a best available approach.

Two theories address how individuals self-attribute various sources of learning outcomes:

a) According to Bem's Self-Perception Theory, "Individuals come to 'know' their own attitudes, emotions, and other internal states partially by inferring them from observations of their own overt behavior and/or the circumstances in which this behavior occurs." ${ }^{21}$ Learning is often influenced by multiple circumstances, or sources, that the learner internally gages as contributing factors to the learned skill or understanding. Overt behavior (behavior easily observed by others) and situational cues (contextual cues in the environment that signal to a person that an action or event may occur) influencing the knowledge learned provide the individual with indications of the perceived impact for each source. Full realization of what accounts for understanding is then linked to what the individual attributes to the understanding.

b) Of additional importance is how individuals attribute certain events to what they know. Attribution Theory explains how individuals attribute various causes to events and behaviors. It is how an individual interprets situational cues and how these cues relate to their thinking and behavior that determines what they hold responsible for the given behavior. ${ }^{22-24}$ A student's belief about where he or she learned a given concept is therefore highly influenced by the importance placed by the student on a specific intervention. 
Student self-perceptions were used to identify the impact their ESE had on their attainment of particular engineering learning outcomes which provided a measure beyond a grading system of knowledge attainment.

\section{Engineering Learning Outcomes}

Engineering institutions (e.g. colleges and universities) have many desired learning outcomes or skills they expect students to learn through undergraduate and graduate level education. Any pedagogical intervention that is introduced into the curriculum should be designed with certain learning goals in mind. ABET, Inc., ${ }^{25}$ recommend that engineering programs must demonstrate that their graduates have:

a. an ability to apply knowledge of mathematics, science, and engineering,

b. an ability to design and conduct experiments, as well as to analyze and interpret data,

c. an ability to design a system, component, or process to meet desired needs,

d. an ability to function on multidisciplinary teams,

e. an ability to identify, formulate, and solve engineering problems,

f. an understanding of professional and ethical responsibility,

g. an ability to communicate effectively,

h. the broad education necessary to understand the impact of engineering solutions in a global and societal context,

i. a recognition of the need for, and ability to engage in, lifelong learning,

j. a knowledge of contemporary issues, and

k. an ability to use the techniques, skills, and modern engineering tools necessary for engineering practice.

Additional learning outcomes were suggested in the 2005 report from the National Academy of Engineering Center for the Advancement of Scholarship on Engineering Education (NAE CASEE). ${ }^{26}$ The report mentions that the engineering education community emphasizes four additional student outcomes:

1. an ability to manage a project, including a familiarity with business, market-related, and financial matters,

m. a multidisciplinary systems perspective,

n. an understanding of and appreciation for the diversity of students, faculty, staff, colleagues, and customers, and

o. a strong work ethic.

Prior to this study, Pierrakos, Borrego, and $\mathrm{Lo}^{27-28}$ used these fifteen criteria to construct a 50-item instrument entitled the "National Engineering Students' Learning Outcomes Survey (NESLOS)." This instrument measured students' perceptions of their technical-engineering subject-matter knowledge generally focused on the application of mathematics, science, and design concepts and professional-personal skills such as communication, teamwork, and lifelong learning outcomes. Items on NESLOS were written to assess knowledge and skills pertaining to, but not limited to: (1) problem-solving, (2) writing and oral communication skills, (3) understanding and applying knowledge, (4) teamwork, (5) confidence gains, (6) organization and management skills, and (7) interest and engagement of project. Two parallel studies were conducted using NESLOS to determine the impact of: (1) engineering senior design projects , 
and (2) cooperative (co-op) experiences on student technical and professional skills. Students used NESLOS to record how helpful the experience was in enabling them to achieve technical and professional skills. Senior capstone project participants identified a greater gain in professional skills than in technical skills. Female students in this sample were shown to have statistically higher ratings for both professional and technical skills than their male classmates. After participating in an engineering co-op experience, participants (mostly rising seniors) had a greater gain in professional skills than in technical skills. Professional skill items were decidedly higher ranked by females.

Pierrakos et al. suggest in their two studies that the use of the NESLOS instrument would greatly enhance our understanding of how students perceive service as a source of learning; however, neither study included any evidence to ensure the validity and reliability of the instrument had been tested and confirmed. The current research intends to extend the work of Pierrakos et al. to not only study perceived learning from service, but to also test and validate the measure.

\section{RESEARCH METHODS}

A nationwide sample of students participating in various forms of engineering service experiences across the United States was assembled for the study to avoid program bias. Students were recruited through a service-based network by asking "authority" figures professors, program managers, and student officers - associated with recognized service courses and programs to identify and solicit their students to participate in the study. To ensure the recruited students had both engineering service and traditional course experiences, the authority figures were asked to confirm their program's alignment with three specific characteristics (shown below) which were derived from the eight criteria defined by Boyer ${ }^{11}$ and Jacoby ${ }^{6}$ :

1. Projects must be authentic to the students. The project can be within a single discipline or multi-disciplinary with components and participants spanning across the disciplines of engineering, math, technology, sciences, arts, and humanities. Projects can be initiated by the academy or by the affected community. The service experience can be practiced under a variety of project scenarios, but requires a formal connection of service and with the learning institution.

2. Service must be intentional and appropriately developed. Service can range from local industry to a developing, rural community. The service is grounded in the needs of the community, but must be jointly developed by all stakeholders, most specifically the students and the affected community. The service effort creates, nourishes and sustains the overall effort. Service is the component that deepens the experience of the project and serves as the basis for the partnership that is developed between the stakeholders' efforts.

3. Learning is the primary goal in carrying out the project and is enhanced by the nature of the service effort. Learning must occur for all stakeholders, but must not be formally assessed. However, planned reflection must occur to bring learning to the forefront and deepen the learning.

The three criteria were used to simplify the authority figure's evaluation of their program. Initial recruitment reached out to students at over 100 institutions across the United States participating in various bonafide ESEs. 
The online survey administered through SurveyMonkey ${ }^{\odot}$ recorded a final sample of 261 undergraduate student responses. Entries excluded from analysis were non-undergraduate engineering student responses, incomplete surveys, and any respondent who rated all items on a given construct scale with the same scores. The last stated reason was employed to avoid using responses done quickly with little thought and consideration for the questions (Note: The items used in this study were a small part of a much larger survey).

The 261 students who comprised the study sample hailed from 87 different institutions across the U.S. with the number of students ranging from two to twenty per institution. Students' ages ranged from 18 to 32 years old $(M=20.5 \pm 2.1)$. Their experience with engineering service ranged from one to four years $(M=1.8 \pm 1.0)$. Students included first-years $(n=30)$, sophomores $(n=54)$, juniors $(n=66)$, and seniors $(n=111)$ majoring in a variety of engineering disciplines (see Table I). The majority of the students were Caucasian $(\sim 77 \%)$ with a close to 1:1 ratio of males to females (132:129).

A random sampling strategy of students that could represent a national sample of engineering service experiences was not used. This strategy was not employed to avoid the expense of carrying out such a process and identifying the exact pool of engineering service experiences offered at thousands of institutions in the U.S. A comparison with the general engineering population also could not be implemented because the male-female composition of the sample indicates proportionally higher numbers of female students possibly participating in engineering service experiences. This is in sharp contrast with the national average of women enrolled in engineering programs across the U.S.

TABLE I.

PARTICIPANT MAJORS

\begin{tabular}{l|c}
\hline Major & $n$ \\
\hline Aeronautics, Astronautics, or Aerospace Engineering & 2 \\
Agricultural Engineering & 1 \\
Bioengineering, Biomedical, or Biosystems Engineering & 26 \\
Chemical Engineering & 29 \\
Civil Engineering & 59 \\
Computer or Software Engineering & 6 \\
Electrical Engineering & 13 \\
Environmental Engineering & 25 \\
General Engineering & 4 \\
Industrial Engineering & 6 \\
Materials or Material Science Engineering & 27 \\
Mechanical Engineering or Engineering Science \& & 56 \\
Mechanics & 1 \\
Ocean Engineering & 3 \\
Systems Engineering & 3 \\
Engineering Psychology, Financial Engineering & 261 \\
\hline
\end{tabular}

\section{Learning Outcomes Assessment}

Instrument Design. The NESLOS instrument was modified to create a new instrument capable of identifying how students perceive different sources of learning. Changes were made to improve 
the validity of the new instrument for the construct related to sources of learning and control the length of the instrument. First, the instrument was condensed from fifty items to sixteen to reduce the amount of time required to complete the entire survey and minimize the number of items it would take to achieve appropriate validation and reliability requirements for the source of learning instrument. Sixteen items were deemed the minimum number of items necessary to ensure that each of the key technical and professional skills identified in the ABET Criterion 3 a$\mathrm{k}$ and NAE CASEE report were still included (see Appendix). The scale was then changed to a 100-point scale with ten unit increments to provide a far more fine-grained assessment of the construct. The overall scale ranging from zero to 100 has been used as a common performance scale throughout educational systems because the population of interest, students, have a comfort level in being scored in school on a 100-point scale. ${ }^{29}$ Finally, the scale required modification in order to identify the impact of their service experience(s) relative to their traditional coursework. This was accomplished with a double-sided scale where the extremes represent $100 \%$ for one intervention and $0 \%$ for the other intervention (e.g. 10CL/90SE represented a response identifying $10 \%$ from traditional coursework learning and $90 \%$ from a service experience. Note: a clear distinction was made in the instructions for students to include a service-learning course experience as a service experience and not a traditional course). A student who chooses the 50CL/50SE option holds the perception that their service experience and their coursework learning have equally accounted for their attainment of the given skill. This way, students were made to compare the two sources of learning directly on the same item. Students were also given the option to associate the given skill with experiences outside of their traditional coursework and service experience by choosing 'I already had that skill.'

Validity and Reliability of the Source of Learning Instrument. Prior to analyzing the student results, the modified-NESLOS instrument was tested for validity and reliability. Confirmatory factor analyses were used to ensure the presence of two underlying factors within the fifteen items. Factor analysis produced two distinct factors (see Table II): 1) technical skills (TS) consisting of six items such as 'apply math, science, and engineering knowledge' (see items 1-6 in Appendix); and 2) professional skills (PS) consisting of ten items such as 'communicate effectively with others' (see items 7-15 in Appendix) - determined using only factors with eigenvalues greater than one. ${ }^{30}$ Reliability for each factor was tested using internal consistency $\left(\alpha_{\mathrm{TS}}=0.846 ; \alpha_{\mathrm{PS}}=0.905\right)$; both factors displayed reliability appropriate for analyzing survey responses. ${ }^{31}$ Further validation and reliability testing was conducted in a previous study. ${ }^{32}$

TS and PS mean factor scores on a scale from zero to 100 were used to estimate students' perception of learning source where lower scores represent greater attributions to traditional courses and higher scores represent greater attributions to service experiences. Mean scores obtained from the instrument were tested using a two-step process. First, multivariate analyses of variance (MANOVA) were used to identify significant differences in perceived learning sources of TS and PS factors from service-related experiences versus traditional courses. In this analysis, gender and academic year were considered as independent variables. Second, if gender or grade level was shown statistically significantly influencing the TS and PS outcomes, then t-tests (used for gender) and 1-way analysis of variance (ANOVA)s (used for academic year) were conducted to further break down the amount of differences among groups identified by gender or grade level. The assumptions for analysis of variance testing were tested to ensure an accurate interpretation of the results. Student responses to the instrument were assumed to be independent. Students' factored scores on TS and PS were normally distributed based on the 
frequency and normal quantile plots, and were homoscedastic based on Box's M test. In other words, the scores displayed statistically equal variances between student groups defined by gender and academic year.

TABLE II

\begin{tabular}{ccc}
\multicolumn{3}{c}{ FACTOR LOADINGS FOR EACH ITEM. } \\
\hline Item & $\begin{array}{c}\text { Factor 1 } \\
\text { (TS) }\end{array}$ & $\begin{array}{c}\text { Factor 2 } \\
\text { (PS) }\end{array}$ \\
\hline 1 & 0.641 & \\
2 & 0.750 & \\
3 & 0.790 & \\
4 & 0.779 & \\
5 & 0.749 & \\
6 & 0.803 & \\
7 & & 0.794 \\
8 & & 0.778 \\
9 & & 0.769 \\
10 & & 0.716 \\
11 & & 0.760 \\
12 & & 0.718 \\
13 & & 0.752 \\
14 & & 0.725 \\
15 & & 0.704 \\
16 & & 0.629 \\
\hline
\end{tabular}

\section{RESULTS}

The first research question asks how service students perceive service as a source of learning relative to traditional coursework. To address this question, an analysis of the mean scores for service as a perceived source of learning TS and service as a perceived source of learning PS was conducted for the 261 engineering service students who participated in the study. Engineering students on average identified that $45 \%( \pm 19.1)$ of what they have learned about technical skills - differentiating between technical skills and technical content - and 62\% ( \pm 18.4$)$ of what they have learned about professional skills was gained through their engineering service experience. This suggests that students perceive their service experience to have contributed to $45 \%$ and $62 \%$ of what they know about technical skills and professional skills, respectively. A closer look at the scores using standardized z-scores reveals a linear trend when professional and technical skills are plotted against one another for each individual student (see Figure 1). The trend suggests that students who believe their service experience to have value toward one set of skills also perceive the experience to have value toward the other set of skills. Vice versa, if students do not see value toward one set of skills they are likely to not perceive value toward the other set of skills. 


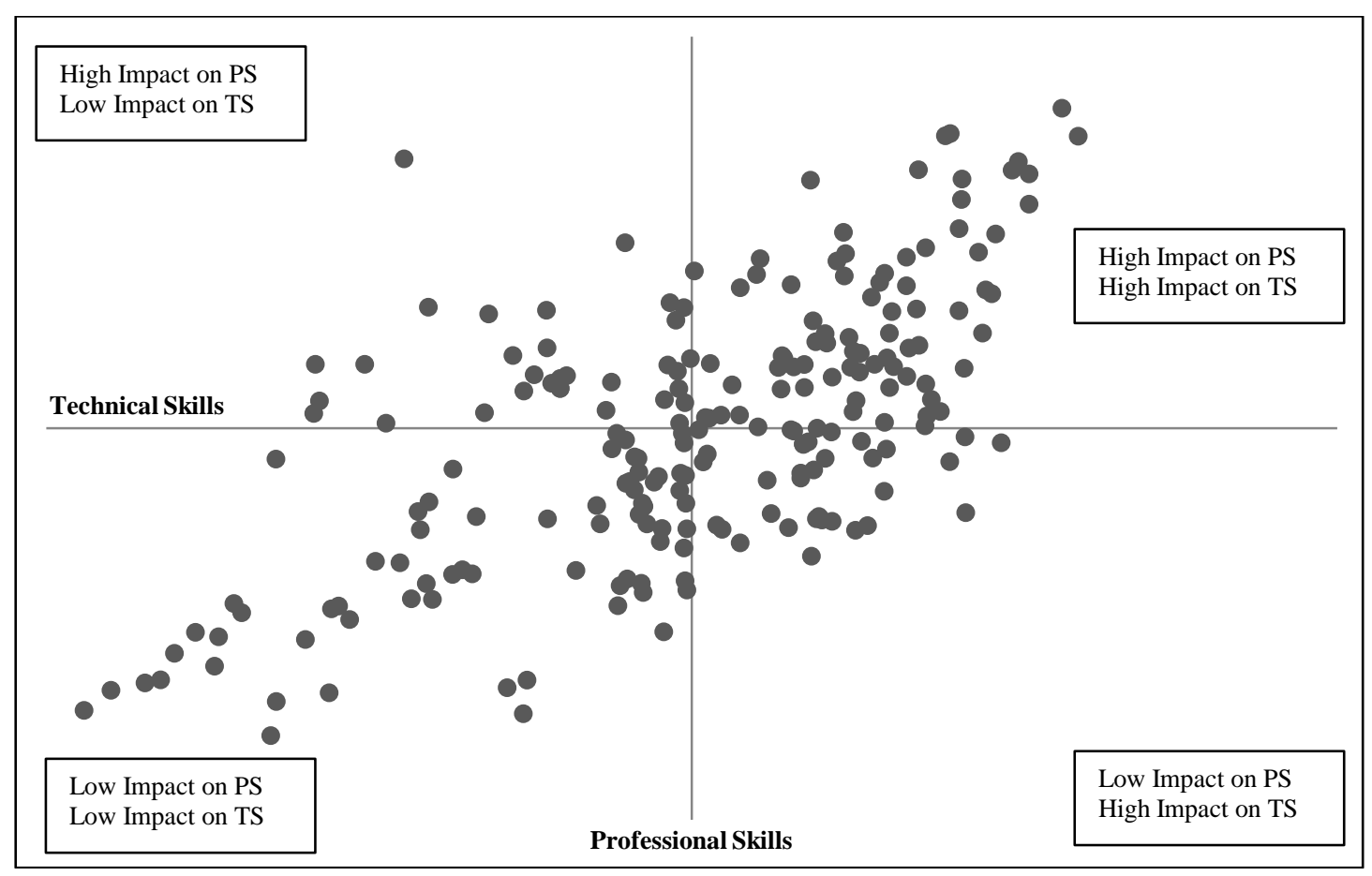

FIGURE 1

STUDENT PROFESSIONAL SKILL (PS) AND TECHNICAL SKILL (TS) Z-SCORES PLOTTED AGAINST ONE ANOTHER CREATING REGIONS OF LOW AND HIGH IMPACT.

Averages varied for perceived learning of technical and professional skills between female and male students as well as across academic years. These differences were further investigated to answer the second research question.

Table III presents the mean scores $(M)$ with standard deviations $(S D)$ in terms of gender and academic year for the sample. The total sample size for each group $(n)$ is noted because students who chose the option 'I already had that skill' were removed from the analysis. This option was chosen for at least one item by less than $5 \%$ of the respondents in the sample.

TABLE III

PERCEIVED SOURCES OF LEARNING FACTOR MEAN SCORES WITH STANDARD DEVIATIONS

\begin{tabular}{c|c|c|c|c|c|c} 
& \multicolumn{3}{c}{ Technical Skills } & \multicolumn{3}{c}{ Professional Skills } \\
\cline { 2 - 7 } & $N$ & $M$ & $S D$ & $n$ & $M$ & $S D$ \\
\hline Gender & & & & & & \\
Males & 126 & $29.9(-0.20)$ & $17.6(0.91)$ & 113 & $42.9(-0.14)$ & $18.6(0.98)$ \\
Females & 123 & $37.6(0.21)$ & $19.8(1.05)$ & 107 & $48.2(0.15)$ & $17.7(1.00)$ \\
\hline Academic Year & & & & & & \\
First-year & 28 & $35.4(0.09)$ & $19.3(1.01)$ & 26 & $42.3(-0.17)$ & $21.5(1.04)$ \\
Sophomores & 49 & $36.1(0.13)$ & $18.7(0.91)$ & 45 & $48.8(0.18)$ & $15.4(0.81)$ \\
Juniors & 63 & $31.6(-0.11)$ & $20.9(1.12)$ & 55 & $43.3(-0.12)$ & $18.6(1.00)$ \\
Seniors & 109 & $33.2(0.02)$ & $18.1(0.96)$ & 94 & $46.0(0.03)$ & $18.9(1.07)$ \\
\hline
\end{tabular}


A two-way MANOVA revealed a significant main effect for gender, but not for academic year (see Table IV). There was no significant interaction effect between gender and academic year. The effect size (partial $E t a^{2}$ ) for gender accounts for $4.2 \%$ of the total variance, which is overall classified as weak; however, power to detect the effect for gender was 0.77 . The results indicate that student perceptions of their source of learning for both TS and PS significantly differed by gender and were not different across academic years.

\section{TABLE IV}

MANOVA SUMMARY TABLE FOR A TWO-WAY BETWEEN-SUBJECTS DESIGN WITH PERCEIVED SOURCES OF LEARNING FACTORS AS OUTCOMES, GENDER AND ACADEMIC YEAR AS PREDICTOR VARIABLES

\begin{tabular}{c|c|c|c|c|c}
\hline Source of Variation & Wilks' Lambda & $d f$ & F ratio & Eta $^{2}$ & Power \\
\hline Gender & 0.958 & 2 & $4.521^{*}$ & 0.042 & 0.766 \\
Academic Year & 0.972 & 6 & 0.998 & 0.014 & 0.396 \\
Interaction & 0.990 & 6 & 0.330 & 0.005 & 0.143 \\
\hline
\end{tabular}

$$
* \rho \leq 0.05
$$

Given the overall significance of gender on the source of learning PS and TS factor-scored variables, the main effects of gender were examined for each factor using independent sample $t$ tests. The Levene's Test, which tests the assumption of equal group error variances, was not significant for technical skills $(p=0.216)$ or professional skills $(p=0.734)$ suggesting the equality of the group variances. The $t$-test results confirmed that the mean scores for females were significantly higher on the technical skills factor $\left[t_{\mathrm{TS}}(248)=3.286, p\right.$ (2-tailed) $\leq 0.001$ ] and professional skills factor $\left[t_{\mathrm{PS}}(219)=2.145, p(2\right.$-tailed $\left.) \leq 0.05\right]$. The $t$-test results suggest that the observed mean differences in Table III for female perceptions of service on their technical and professional skills is significantly greater than their male classmates.

The lack of an overall significance of academic year and the interaction on the PS and TS factor variables was also further examined using ANOVA and mean plots. The one-way ANOVA results confirmed the lack of a significant effect of academic year on the perceived sources of learning for the TS factor $\left[F_{\mathrm{TS}}(3,248)=0.651, p=0.583\right]$ and the PS factor $\left[F_{\mathrm{PS}}(3\right.$, $219)=1.038, p=0.377]$. The results suggest that service students at any academic year perceive their service experience to have the same level of impact on their learning of technical and professional skills throughout their academic engineering education.

The mean plots of the technical (see Figure 2) and professional skills (see Figure 3) factors for males and females across academic year were plotted to test the lack of a significant interaction between gender and academic year. The similar gender gap across the academic years for both the technical and professional skills factors visually displays no interaction exists between gender and academic year. This was confirmed using a two-way ANOVA of the interaction (gender*academic year) $\left[F_{\mathrm{TS}}(3,248)=0.406, p=0.749 ; F_{\mathrm{PS}}(3,219)=0.212, p=\right.$ $0.888]$. 
International Journal for Service Learning in Engineering Vol. 8, No. 1, pp. 1-17, Spring 2013

ISSN 1555-9033

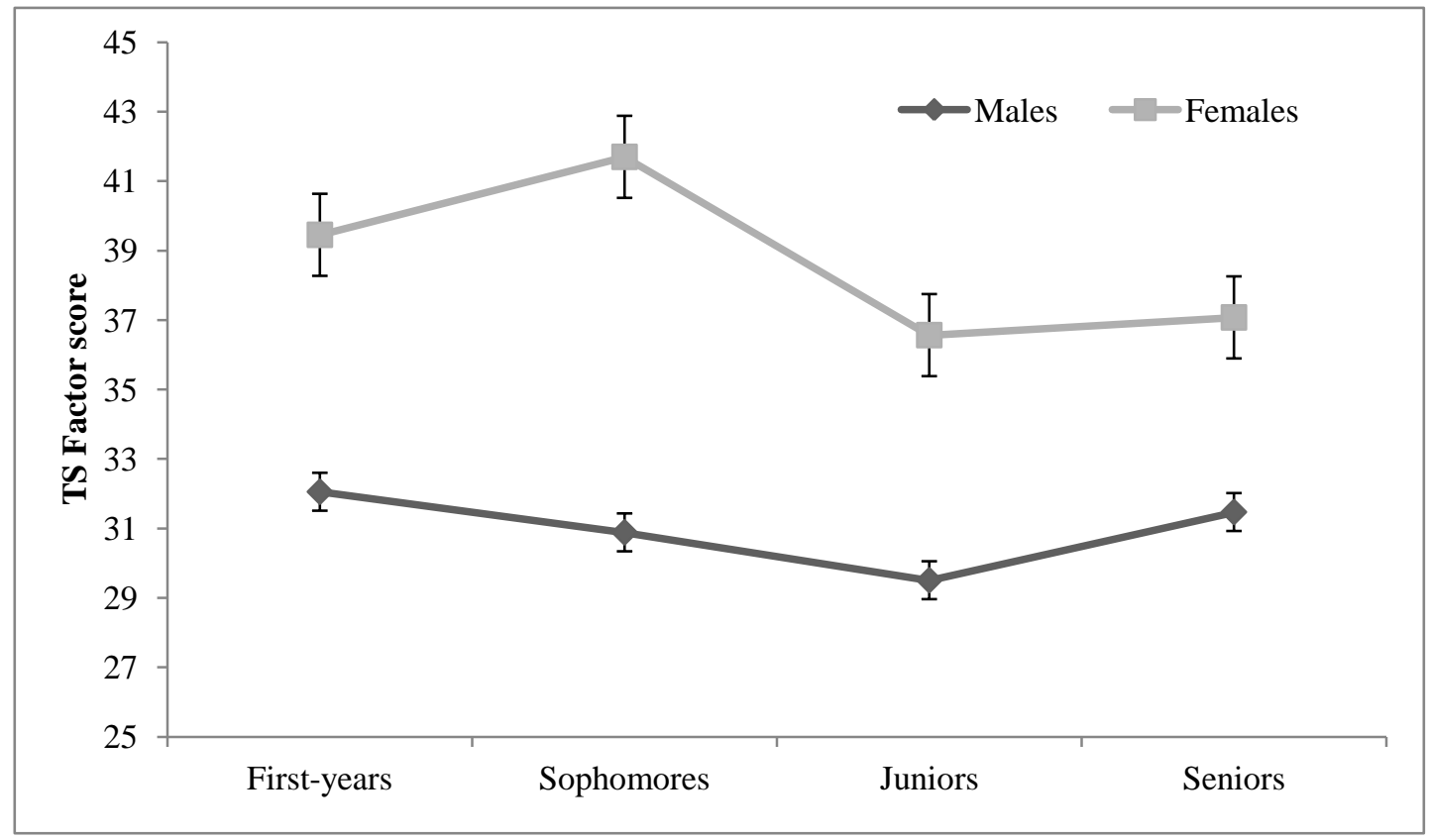

FIGURE 2

MEAN TECHNICAL SKILLS FACTOR SCORES WITH STANDARD ERROR FOR EACH GENDER ACROSS ACADEMIC YEAR

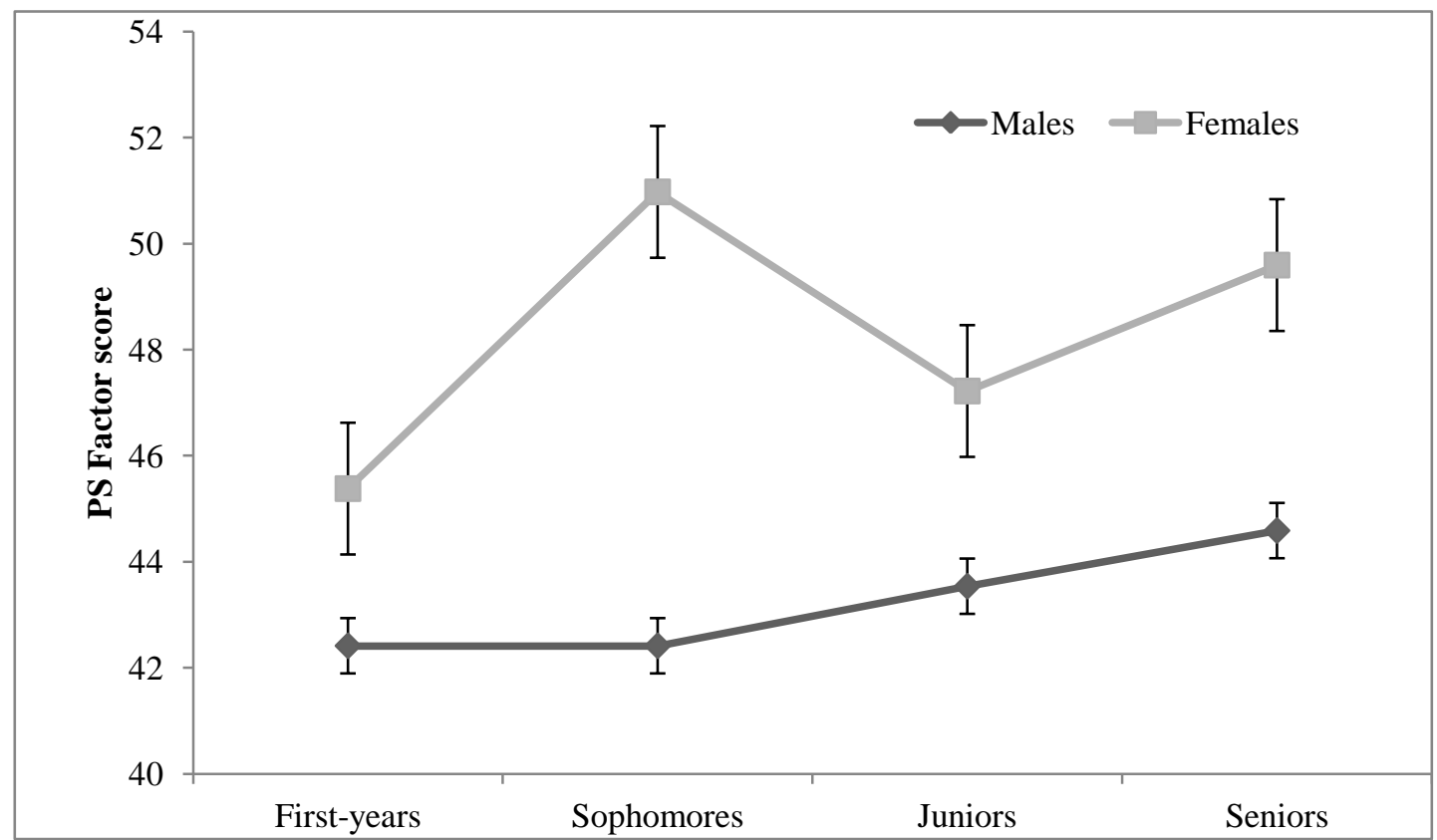

FIGURE 3

MEAN PROFESSIONAL SKILLS FACTOR SCORES WITH STANDARD ERROR FOR EACH GENDER ACROSS ACADEMIC YEAR 


\section{DISCUSSION}

The student sample perceiving service to account for $62 \%$ of what they learned about professional skills and $45 \%$ of what they learned about technical skills relative to traditional coursework learning suggests value in service offerings. Students crediting service as a source of learning professional skills more than technical skills is to be expected because the aim of many service experiences is to make the practice of professional skills a major component of the experience. Traditional coursework can often overlook the importance and need for students to learn professional skills. The results may relate to many courses teaching engineering science topics from an abstract theoretical perspective rather than a practical approach. The approach neglects the need for context and connections to the real world, which contrarily is a major tenant of service experiences. Real world professional skills may be learned more effectively through service because such experiences try to make the learning of professional skills visible to students.

While traditional coursework learning was identified to have a larger impact for technical skills, the relative time (e.g. one semester compared to 8 semesters) spent on service compared to traditional coursework suggests service to be an important experience in this cohort of students' engineering education. Students in this sample varied from one to four years of participation in anywhere from one to two different service experiences. Regardless of time and type of experience, the identified linear relationship showed students to have typically felt the same way about the impact of service on technical and professional skills whether positive or negative. This result could be tied to the use of various engineering service experiences or it could suggest that service experiences are not the best means of learning for all engineering students. We believe that the type of service experience is not the reasoning behind the perceived value toward learning, but instead based on student expectations for the type of educational experiences they receive. The interests and learning styles of students weighs heavily on whether such experiences are effective.

Gender analysis identified those female students who participated in learning through service opportunities rated the contribution of service experiences to their learning of both technical and professional skills significantly higher than their male classmates. This finding can be explained by the reported tendency of females, more so than males, to seek activities that help people. ${ }^{33,34}$ This could be one reason, as demonstrated by the voluntary sample obtained for this study, for why females are highly attracted to service opportunities as part of their academic engineering education. As a result, this research also suggests that service experiences can be used to attract females into STEM disciplines.

An analysis across academic year identified that there were no significant differences between the perceptions of first-years, sophomores, juniors, and seniors regarding the impact of service. This suggests that a service experience can be undertaken at any point in a students' higher education resulting in the same perceived contribution to their technical and professional skills. The effect also shows that current service experience offerings do not expand across academic years. This may change if more opportunities are present allowing more students to participate in more hours as they move to higher-grade levels. A longitudinal study of programs like UMass-Lowell's Service Learning Integrated throughout the College of Engineering (SLICE) program, which implements a series of service experiences for students throughout the curriculum, would be an interesting analysis to provide an in-depth understanding of gained professional skills. 
What this study reveals is a need for service experiences to address the ABET and NAE outcomes often overlooked in traditional coursework. Engineering degree programs often talk about developing students into well-rounded individuals by requiring them to take courses in the humanities. If we want engineering students to develop into more conscious and active citizens we should look to service experiences as an approach to integrate such disciplines into real projects in order to achieve this goal.

\section{LIMITATIONS}

This study was intended to observe students perceptions of service experiences from a collective perspective. The conscience decision to combine a variety of service experiences into one group without a control group was purposefully conducted to avoid service-type bias. Grouping all service experiences together accomplishes a general assessment of service, but does include some drawbacks. One limitation is the inability to separate students participating in different types of programs at different institutions. The smaller impact on technical skills compared to the impact on professional skills may be related to the type of service and the environment in which the service occurs. While learning of technical skills is always implicit in the activities that engineering service students perform, the rigorous education of technical skills is not always an enforced requirement of some extracurricular service activities. This could in fact diminish the learning of technical skills for some experiences. These groups were not separated in part to show an overall effect rather than a programmatic impact. Studying a larger group of students at one institution with a variety of service opportunities would combat this limitation; however, it is rare that students who participate in service opportunities only participate in the service experience without simultaneously taking traditional courses.

The second limitation of the study is the use of student perceptions to identify change. Student bias, both positive and negative, toward their service or traditional course experiences may exist prohibiting them from accurately attributing the circumstances that occur in their lives. Their perceptions can be skewed by their inability to truly identify the root cause of a learned skill. The assessment of service experiences and other new forms of educational practices requires a new, not yet formulated learning paradigm. ${ }^{35}$ Most service experiences occur in parallel with traditionally taught courses. Student perceptions are in essence the best means to measure impact at this time. A control group could be added, but was ruled out in this study because an equivalent sample of self-selecting students does not truly exist. Students who participate in other extracurricular engineering activities or only non-service coursework learning would fail to fully control for the differences of service students. Even studying the same students longitudinally would present the impossible task of extracting the impact of the service alone. A true control group would only be possible if a course were taught with half of the students randomly being assigned to a service version and the other half being assigned to a coursework only version. This approach is feasible, but viewed by the authors as an unfair experience for the students who may or may not desire a service experience. A follow-up study that determines an appropriate control group would be interesting to further validate these results if an equivalent group could be determined. 


\section{CONCLUSIONS \& IMPLICATIONS}

This study was designed to investigate the perceptions students have about the impact of service on their learning. Academic engineering education affords engineering students with a variety of experiences designed to learn recommended technical and professional skills. The analysis of this particular cohort of engineering students identified service to have a substantial impact on their learning no matter the proximity to the classroom, for how long they participated, or at what stage in their education they participated in the experience. Students identified that $45 \%$ of what they learned about technical skills and $62 \%$ of what they learned about professional skills was learned through their service activity. The impact was identified to be even more important for females (49\% for TS and 65\% for PS) who identified significantly higher perceptions of service as a source of learning compared to their male classmates (41\% for TS and 59\% for PS).

Based on the positive student perceptions of service as a source of learning, engineering educators should be encouraged by the identified effects of service as a pedagogical approach. The perceived impact on professional and technical skill learning suggests that any form of service can provide a useful pedagogical strategy or educational intervention for many engineering students and may facilitate the attainment of learning outcomes currently advocated by ABET. The value placed on these opportunities by this sample of students should be considered encouraging when deciding the direction of a given institution's engineering education and should drive institutions to implement and offer service experiences for their students.

\section{ACKNOWLEDGEMENTS}

This work was supported by the National Science Foundation Engineering Education Program (EEC) Grant No. EEC-0835981. Any opinions, findings, and conclusions or recommendations expressed in this material are those of the author(s) and do not necessarily reflect the views of the National Science Foundation. The authors would also like to thank Matthew Ohland, Chris Rogers, and Judah Schwartz for their insights into the findings of this study.

\section{REFERENCES}

1 McCahan, S., Ault, H.K., Tsang, E., Henderson, M.R., and S.P. Magleby. "A multi-dimensional model for the representation of learning through service activities in engineering." Proceedings of the American Society for Engineering Education Annual Conference \& Exposition, San Antonio, TX, 2012.

2 Bringle, R.G., and J.A. Hatcher. "Implementing Service Learning in Higher Education." Journal of Higher Education, 67, no. 2, 1996.

3 Bringle, R. G. and J.A. Hatcher, J. A. "Innovative practices in service-learning and curricular engagement." New Directions for Higher Education, 147, pp. 37-46, 2009.

4 Eyler, J., and D.E. Giles. Where is the learning in service-learning. San Francisco, CA: Jossey-Bass, 1999.

5 Furco, A. Service Learning: A Balanced Approach to Experiential Education. Washington, D.C.: Corporation for National Service, 1996.

6 Jacoby, B. “Service-learning in today's higher education”. In B. Jacoby \& Associates (Eds.), Service-learning in higher education (pp. 5-13). San Francisco, CA: Jossey-Bass, 1996.

7 Morgan, W. and M. Streb. "Promoting civic activism: Student leadership in service learning." Politics and Policy, 30, no. 1, pp. 161-188, 2002.

8 Rhoads, R. A. and J. Howard, J. (Eds.). Academic service learning: A pedagogy of action and reflection. San Francisco, CA: Jossey-Bass, 1998.

9 Shumer, R. Defining service learning: A delphi study. St. Paul, MN: Center for Experiential Education and Service Learning. College of Education, University of Minnesota, 1993. 
${ }^{10}$ Sigmon, R. "Service-learning in North Carolina." New Directions for Higher Education 6, pp. 23-30, 1974

${ }^{11}$ Boyer, E.L. "Service: Linking school to life." Community Education Journal, 15, no. 1, 7-9, 1987.

${ }^{12}$ Harding, J. "Values, Cognitive Style, and Curriculum." In Contributions to the Third Girls and Science and Technology Conference. London: University of London, Chelsea College, 1985.

${ }_{13}^{13}$ Dewey, J. Education and Experience. New York, NY: Simon and Schuster, 1938.

${ }^{14}$ Wutzdorff, A. and D. Giles. "Service learning in higher education." In J. Schine (Ed.), Service learning: Ninetysixth yearbook of the National Society for the Study of Education (pp. 105-177). Chicago, IL: National Society for the Study of Education, 1997.

${ }^{15}$ Tsang, E., Martin, C.D., and R. Decker. "Service-Learning as a Pedagogy for Engineering Education for the 21st Century." Proceedings of the American Society for Engineering Education Annual Conference \& Exposition, Milwaukee, WI, 1997.

${ }^{16}$ Duffy, J.J. "Service-Learning in a Variety of Engineering Courses." In E. Tsang (ed.), Design That Matters: Service-Learning in Engineering, American Association of Higher Education, Washington, DC, 2000.

${ }^{17}$ Boyer, E. L. Scholarship reconsidered: Priorities of the professoriate. San Francisco, CA: Jossey-Bass, 1990.

${ }^{18}$ Boyer, E.L. Creating the new American college. Chronicle of Higher Education, A48, 1994.

${ }^{19}$ Barrington, L. and J. Duffy, "Maximizing benefits of service-learning in engineering." Proceedings of the American Society for Engineering Education Annual Conference \& Exposition, Louisville, KY, 2010.

${ }^{20}$ Bielefeldt, A.R., Paterson, K.G., \& Swan, C.W. "Measuring the value added from service learning in projectbased engineering education." International Journal of Engineering Education, 26, no. 3, pp. 535-546, 2010.

${ }^{21}$ Bem, D.J. "Self-Perception Theory." In L. Berkowitz (ed.), Advances in Experimental Social Psychology (pp. 162). New York, NY: Academic Press, 1972.

${ }^{22}$ Jones, E.E., D. E. Kannouse, H.H. Kelley, R.E. Nisbett, S. Valins, and B. Weiner. Attribution: Perceiving the Causes of Behavior. Morristown, NJ: General Learning Press, 1972.

${ }^{23}$ Weiner, B. Achievement Motivation and Attribution Theory. Morristown, NJ: General Learning Press, 1974.

${ }^{24}$ Weiner, B. "An Attributional Theory of Achievement, Motivation, and Emotion." Psychological Review, 92, pp. 548-73, 1986.

${ }^{25}$ ABET Engineering Criteria 2000, http://www.abet.org.

${ }^{26}$ Bjorklund, Stefani, and Norman L. Fortenberry. Final Report: Measuring Student and Faculty Engagement in Engineering Education. Center for the Advancement of Scholarship on Engineering Education (CASEE): National Academy of Engineering, 2005.

${ }^{27}$ Pierrakos, O., M. Borrego, and J. Lo. "Assessing Learning Outcomes of Senior Mechanical Engineers in a Capstone Design Experience." Proceedings of the American Society for Engineering Education Annual Conference \& Exposition, Honolulu, HI, 2007.

${ }^{28}$ Pierrakos, O., M. Borrego, and J. Lo. "Preliminary Findings from a Quantitative Study: What Are Students Learning During Cooperative Education Experiences?" Proceedings of the American Society for Engineering Education Annual Conference \& Exposition. Pittsburgh, PA, 2008.

${ }^{29}$ Pajares, F., J. Hartley, and G. Valiante. "Response Format in Writing Self-Efficacy Assessment: Greater Discrimination Increases Prediction." Measurement and Evaluation in Counseling and Development, 33, pp. 21421, 2001.

${ }^{30}$ Rummel, R.J. Applied Factor Analysis. Evanston, IL: Northwestern University Press, 1970.

${ }^{31}$ George, D. and P. Mallery. SPSS for Windows step by step: A simple guide and reference 11.0 update ( $4^{\text {th }}$ ed.). Boston: Allyn \& Bacon, 2003.

${ }^{32}$ Carberry, A.R. and C.W. Swan. "Developing an instrument to measure the impact of service on technical and professional learning outcomes." Proceedings of the American Society for Engineering Education Annual Conference \& Exposition, Vancouver, B.C., 2011.

${ }^{33}$ Sax, L.J. "Retaining Tomorrow's Scientists: Exploring the Factors that Keep Male and Female College Students Interested in Science Careers." Journal of Women and Minorities in Science and Engineering, 1, pp. 45-61, 1994.

${ }^{34}$ Miller, P.H., S.V. Rosser, J.P. Benigno, and M.L. Zieseniss. "A Desire to Help Others: Goals of HighAchieving Female Science Undergraduates." Women's Studies Quarterly, 1 \& 2, pp. 128-142, 2000.

${ }^{35}$ Young, C. O. and L.H. Young. "Assessing learning in interactive courses." Journal on Excellence in College Teaching, 10, no. 1, pp. 63-76, 1999. 


\section{APPENDIX - Modified National Engineering Students' Learning Outcomes Survey (NESLOS)}

Directions: Rate how helpful your engineering service experience (SE) was compared to your coursework learning $(C L)$ in enabling you to achieve the following skills. Choose the option that best depicts the percent impact from engineering learning-through-service and coursework.

Ex. 10CL/90SE $=10 \%$ impact from coursework/90\% impact form engineering service experiences OCL/100SE $60 \mathrm{CL} / 40 \mathrm{SE}$

10CL/90SE $70 \mathrm{CL} / 30 \mathrm{SE}$

20CL/80SE

$80 \mathrm{CL} / 20 \mathrm{SE}$

30CL/70SE

90CL/10SE

40CL/60SE

100CL/OSE

$50 \mathrm{CL} / 50 \mathrm{SE}$

I already had that skill (please list from where)

1. Apply math, science, and engineering knowledge.

2. Design a system, component, or process to meet desired needs.

3. Design an experiment.

4. Analyze and interpret data.

5. Apply techniques, skills, and modern engineering tools in practice.

6. Conduct (or simulate) an experiment.

7. Communicate effectively with others.

8. Operate in the unknown (i.e. open-ended design problems).

9. Function within a team

10. Engage in critical, reliable, and valid self-assessment (i.e. reflection).

11. Persevere to complete an engineering design task.

12. Maintain a strong work ethic throughout an engineering design project.

13. Understand the impact of your engineering design/solution in a societal and global context.

14. Identify potential ethical issues and dilemmas of a project.

15. Knowing what you want to do after graduation (get a job, go to graduate school, etc...)

16. Recognize the need for life-long learning 